\title{
PRINCIPAIS PATOLOGIAS ESTRUTURAIS E ATUAIS METODOLOGIAS DE CONTROLE NA CONSTRUÇÃO CIVIL
}

\section{MAIN STRUCTURAL PATHOLOGIES AND CURRENT CONTROL METHODOLOGIES IN CIVIL CONSTRUCTION}

\author{
Murilo Marques de Souza ${ }^{1}$ \\ ${ }^{1}$ Bacharelando em Engenharia Civil - 7ํ Período. Faculdade Panamericana de Ji- \\ Paraná UNIJIPA. E-mail: murilomarquesouza@hotmail.com
}

RESUMO: Patologias na construção civil podem ser entendidas como doenças que comprometem a estrutura em relação a sua estabilidade, estética e principalmente durabilidade. Os fenômenos patológicos geralmente apresentam manifestação externa característica, a partir da qual se pode deduzir a natureza, a origem e os mecanismos envolvidos. Algumas manifestações patológicas têm maior incidência, justamente devido a uma considerável necessidade de cuidados que frequentemente são ignorados. A patologia das estruturas pode ser considerada um novo ramo do conhecimento da engenharia estrutural e encontra-se em acelerado desenvolvimento, seja no que se refere a novas pesquisas, ou em relação a novos produtos que são frequentemente lançados no mercado, ou ainda pela capacitação de profissionais. Apesar do avanço tecnológico no campo das técnicas e dos materiais de construção, tem-se observado um expressivo número de edificações relativamente novas, apresentando patologias em sua estrutura. Neste contexto, o surgimento de manifestações patológicas nas edificações, causam grandes desconforto aos clientes. Assim, este trabalho apresentará análises às principais manifestações patológicas que puderam ser evidenciadas com o objetivo de expor análises e pontos de vista dos mais diversos autores através dos métodos construtivos e intervenções mais efetivas para que as mesmas sejam reduzidas ou cessem.

PALAVRAS-CHAVE: Patologias; Durabilidade; Estruturas.

ABSTRACT: Pathologies in civil construction can be understood as diseases that compromise the structure in relation to their stability, esthetics and mainly durability. The pathological phenomena usually present characteristic external manifestation, from which it can be deduced nature, origin, and mechanisms involved. Some pathological manifestations have a higher incidence, precisely because of a considerable need for care that is often ignored. The pathology of structures can be considered a new branch of knowledge of structural engineering and is in quick development, whether in regard to new research or in relation to new products that are often launched on the market or yet for the training of professionals. Although of technological advancement in the field of techniques and construction materials has been observed an expressive number of relatively new buildings showing pathologies in its structure. In this context, the appearance of pathological manifestations in buildings causes great discomfort to costumers. As soon, this work will present analyzes to the main pathological manifestations that could be evidenced with the objective of expose analyzes and points of view of the most diverse authors through construction methods and more effective interventions so that they are reduced or cease.

KEY WORDS: Pathologies; Durability; Structures. 


\section{INTRODUÇÃO}

Os elementos da construção civil podem facilmente ser comparados as ciências médicas quando o tema abordado refere-se as patologias que as construções são acometidas, assim como o corpo humano as obras de engenharia estão sujeitas a disfunções patológicas sejam elas estruturais ou de revestimento que afetam somente a estética da edificação.

Uma edificação é composta pelo conjunto de materiais e de processos construtivos em cadeia e nesta heterogeneidade de processos apresentam os principais pontos de formação de patologias, é possível observar na classificação e avaliação da qualidade dos materiais ou ausência de mão-de-obra qualificada para o serviço de engenharia.

De origem grega o termo patologia que é definido como "estudo das doenças" foi amplamente difundido no campo da engenharia, devido a fácil compreensão dos termos e entendimento. Baseado principalmente na relação humano/edificação, os sistemas de sustentação, morfologia e proteção são bem similares para utilização em analogias práticas.

A engenharia diagnóstica é um campo de estudo da engenharia que objetiva analisar, prever, classificar e determinar medidas de controle e recuperação das edificações que apresentam manifestações patológicas. A deformações estruturais caracterizam-se como uma das áreas de maior atenção neste ramo, é de extrema importância determinar os esforços solicitantes da estrutura e determinar os pontos que estarão mais solicitados por carregamentos.

Flechas excessivas, fissuras, trincas e a deterioração propriamente dita do concreto são os principais sintomas decorrentes das patologias. $O$ objetivo principal desta pesquisa é esclarecer as principais patologias estruturais presentes na construção civil e suas respectivas causalidades.

\section{CONCEITUAÇÃO}

As patologias no ambiente da construção civil podem ocorrer em uma das três principais fases de construção de uma edificação: projeto, execução e utilização [1]. Esta divisão de ocorrências é exemplificada de forma mais específica pela tabela 1 onde descreve em percentuais a possiblidade de patologias [2]. 
Tabela 1 - Ocorrência de patologias de acordo com as fases de construção

\begin{tabular}{cc}
\hline Fase de edificação & Ocorrência de Patologias \\
\hline Projeto & $18 \%$ \\
Materiais & $6 \%$ \\
Execução & $52 \%$ \\
Utilização & $14 \%$ \\
Outros & $10 \%$ \\
\hline
\end{tabular}

Fonte: [2]

Dentre os principais erros que podem ocasionar patologias estão à ausência de detalhamento em projetos, dimensionamento incorreto, incompatibilização de projetos, erro na interpretação de projetos, ausência de controle técnico, má execução de cimbramentos e principalmente ausência de fiscalização adequada durante o processo construtivo da edificação [3], exemplificada conforme a tabela 2: Tabela 2 - Ocorrência de patologias de acordo com as fases de construção

\begin{tabular}{cc}
\hline Manifestação Patológica & Ocorrência (\%) \\
\hline Deterioração e degradação química da & $7 \%$ \\
construção & $10 \%$ \\
Deformações (flechas e rotações) excessivas & \\
Segregação dos materiais componentes do & $20 \%$ \\
concreto & $20 \%$ \\
Corrosão das armaduras de concreto armado & $21 \%$ \\
Fissuras e trincas ativas ou passivas & $22 \%$ \\
Manchas na superfície do concreto &
\end{tabular}

Fonte: [3]

As patologias podem ser classificadas e conceituadas a partir da sua manifestação sintomática externa exemplificada a partir da definição correta dos sintomas é possível determinar a origem e como a patologia pode afetar negativamente a eficiência da estrutura, reduzindo a vida útil da construção ou impossibilitando a sua utilização [2].

Conforme apresentado pela NBR 6118:2003, no item 5.1.2.3, durabilidade "consiste na capacidade da estrutura resistir às influencias ambientais previstas e definidas em conjunto pelo autor do projeto estrutural e o contratante, no início dos trabalhos de elaboração do projeto". Outro ponto relativo à durabilidade previsto na NBR está no item 6.1, refere-se as estruturas de concreto que "devem ser 


\section{ARTIGO DE REVISĀO I review article}

projetadas e construídas de modo que sob as condições ambientais previstas na época do projeto e quando utilizadas conforme preconizado em projeto, conservem sua segurança, estabilidade e aptidão em serviço durante o período correspondente à sua vida útil" [4].

Por sua vez, a NBR 15575:2013, apresenta o termo "durabilidade" como o período em que o edifício e seus sistemas exercem as funções para o qual foram dimensionados, ou seja a partir do início da degradação, a estrutura deixa de cumprir sua função apresentando um resultado insatisfatório de desempenho [5].

A durabilidade é descrita como não somente uma característica dos materiais, mas um resultado da interação de um material ou componente com o meio ambiente. Também afirma que esta interação provoca alterações na capacidade de atendimento das demais necessidades dos usuários ocasionado a degradação da estrutura [3].

"Vida útil de projeto" pode ser classificada como o período de tempo em que a estrutura apresenta condições aceitáveis de aparência, funcionalidade e segurança, ou seja, todos os requisitos mínimos para o qual a estrutura foi dimensionada. Por sua vez o termo "durabilidade das construções" é definido pela capacidade de uma estrutura manter as qualidades e características estruturais em seu período de vida útil [2].

As patologias em sua grande maioria são decorrentes do desenvolvimento acelerado da tecnologia, ou seja, por diversas vezes profissionais buscam em softwares o dimensionamento mais econômico e falham neste processo, seja nas especificações de materiais ou nas dimensões dos elementos estruturais. $O$ processo de perda de qualidade das estruturas através do envelhecimento natural ou por causas acidentais é definido como processo de deterioração estrutural [6].

O conceito de desempenho das edificações é reafirmado como sendo o seu comportamento durante a fase de utilização em um determinado período de tempo, também descreve a importância de seu estudo para a segurança e o bem estar do indivíduo ou grupo de indivíduos que utilizam a edificação. A ausência de aplicação das normas de desempenho das edificações infere a responsabilidade de sua não aplicação aos agentes do setor que ainda não criaram uma cultura de previsão e precipitação para evitar custos posteriores ocasionados por patologias, que poderiam facilmente ser prevenidas com manutenção e recuperação estrutural [7]. 
O termo de "patologias das estruturas" é descrito como não somente um mecanismo de identificação das anomalias, mas um processo análises dos projetos, desde a sua concepção até a utilização da edificação. Traz a problemática que a formação do engenheiro civil é baseada no dimensionamento (fase de projeto) e execução das estruturas, deixando uma parcela importantíssima da engenharia descoberta, a reabilitação estrutural [6].

Outro ponto base da engenharia diagnóstica é a atenção prioritária ao conforto de um cliente direto, sem que o bem-estar coletivo seja dado o devido enfoque. Em projetos de engenharia a durabilidade das construções devem estar em destaque, pois casos existam posteriormente patologias estruturas seus custos não são facilmente mensuráveis e podem ocasionar a demolição da estrutura parcialmente ou total [6].

O projeto e a execução de obras de engenharia baseiam-se principalmente na obtenção de resistência satisfatórias das peças estruturais que serão solicitadas pela estrutura fazendo-se necessário a observação mínima dos conceitos de serviço afim de evitar fissurações, deformações e curvaturas excessivas [7].

\section{PRINCIPAIS PATOLOGIAS ESTRUTURAIS}

As principais patologias estruturais são ocasionadas principalmente por recalques das fundações, dilatações térmicas excessivas, sobrecargas ou acúmulos de tensões, retração do concreto, carbonatação, deformações acima do permissível em peças estruturais, defeitos construtivos, entre outros [7].

\subsection{DIAGNÓSTICO DE FISSURAS E TRINCAS}

O processo de diagnóstico de trincas é considerado uma atividade minuciosa através de ensaios laboratoriais, revisão de projetos e avaliação por profissionais especializados [7]. Uma patologia pode ser identificada e diagnosticada a partir de três etapas:

- Levantamento das informações necessárias para entendimento dos fenômenos por completo; 


\section{ARTIGO DE REVISÃO I review article}

- Entendimento dos fenômenos, buscando estabelecer as relações de causalidade e consequências que normalmente descrevem o processo patológico;

- Diagnóstico do problema, bem como elaboração de relatórios que exemplifique as ações de recuperação para solução da patologia ou estabilização do processo de deterioração da edificação [7].

Para identificação de uma trinca devem ser quantificadas a sua incidência em uma edificação, bem como o comprimento, abertura, localização na estrutura. Outras informações complementares que podem ser obtidas são as idades aproximadas da trinca, a existência de outras trincas paralelas e a similaridade de trincas em edificações vizinhas. É importante observar se a trinca já foi recuperada em algum outro momento da vida útil da construção e se existe um condicionamento quanto as estações do ano, conhecido como condicionamento sazonal [7].

O principal motivo para o surgimento de trincas está associado a movimentações em geral da estrutura. Atualmente existem equipamentos como clinômetros, defletômetros e extensômentos (fig. 1) para acompanhamentos dos recalques.
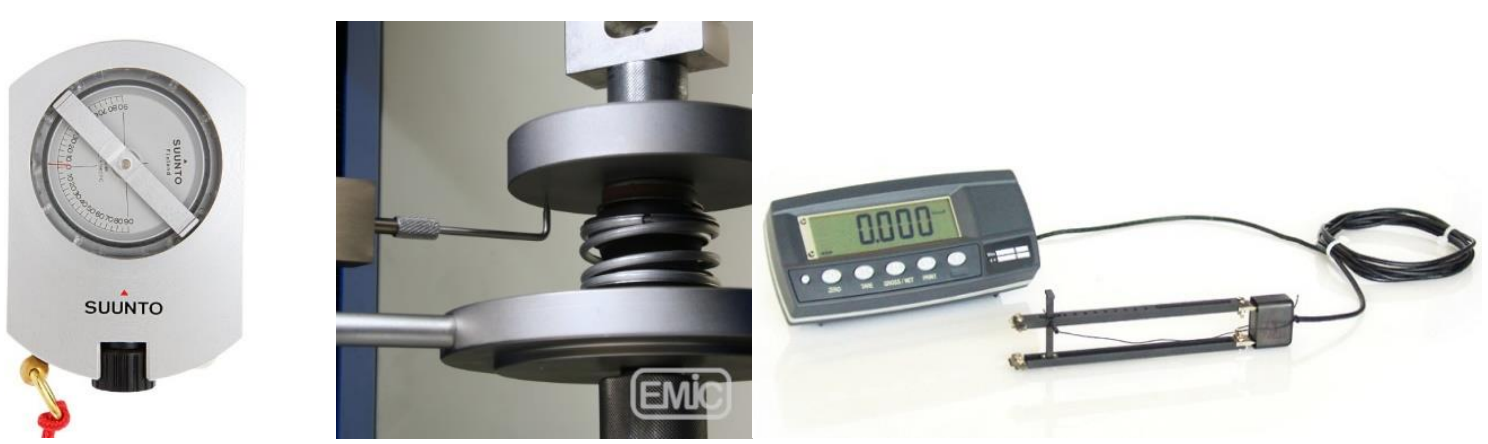

Figura 1 - Clinômetro, defletômetro e extensômetro. Fonte: [7]

Outra forma, considerada mais simples para o diagnóstico e avaliação de trincas utiliza o método de "testemunhas" (fig. 2), seja de vidro ou metal, consiste em fixar um material rígido entre a fissura com traços de referência objetivando quantificar os deslocamentos e se ainda existe continuidade nos movimentos estruturais [7]. 


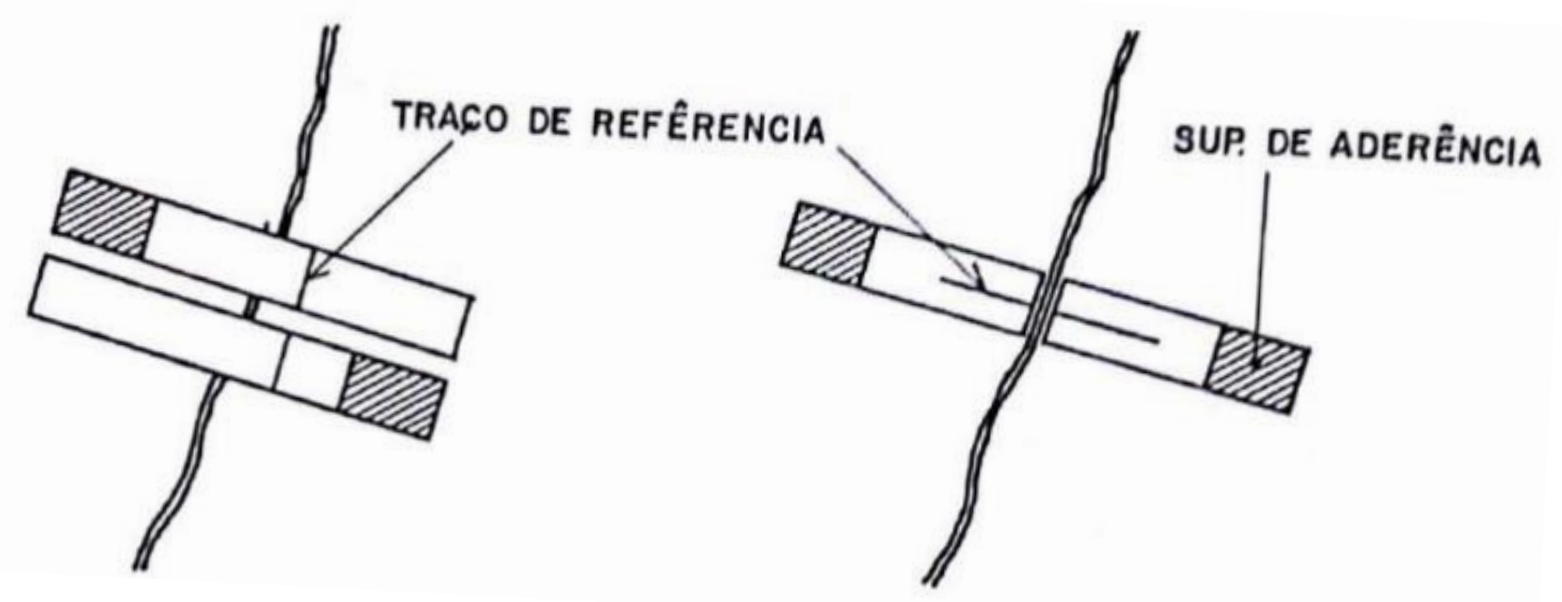

Figura 2 - Testemunhas verticais e horizontais. Fonte: [7]

Uma das formas iniciais de diagnóstico de trincas e fissuras refere-se a sua classificação sendo este um dos mecanismos que possibilitam o profissional determinar qual será o procedimento correto para a patologia identificada. A classificação das rupturas e fissuras [1] podem ser realizadas conforme a tabela 3 a seguir:

Tabela 3 - Classificação de fissuras e trincas

\begin{tabular}{cc}
\hline Tipo & Espessura $(\mathbf{m m})$ \\
\hline Fissura capilar & menos de $0,2 \mathrm{~mm}$ \\
Fissura & de $0,2 \mathrm{~mm}$ à $0,5 \mathrm{~mm}$ \\
Trinca & de $0,5 \mathrm{~mm}$ à $1,5 \mathrm{~mm}$ \\
Rachadura & de $1,5 \mathrm{~mm}$ à $5 \mathrm{~mm}$ \\
Fenda & de $5 \mathrm{~mm}$ a $10 \mathrm{~mm}$ \\
Brecha & mais de $10 \mathrm{~mm}$ \\
\hline
\end{tabular}

FONTE: [7]

\subsection{CORROSÃO DE ARMADURAS E CONCRETO}

A corrosão de armaduras é um processo definido, como sendo um processo eletroquímico que acelera-se na presença de outros agentes químicos sejam eles internos ou externos ao concreto. $O$ concreto propicia um ambiente básico para 0 aço e por consequência um sistema de proteção para as armaduras [8]. 


\section{ARTIGO DE REVISĀO I review article}

Com a fissuração da estrutura ou algum outro material que não deveria estar presente na massa do concreto, esta barreira de proteção é atravessada permitindo o contato de sulfatos, sulfetos e cloretos com a armadura, iniciando o processo de corrosão [8].

Os primeiros sintomas identificados em uma estrutura que apresenta corrosão de armaduras são manchas de óxidos na superfície do concreto, geralmente é acentuando em estruturas que possuem um grau elevado de umidade facilitando ainda mais o processo de propagação [3].

A partir do momento que são criados os óxidos e hidróxidos estes ocupam um volume de aproximadamente oito a dez vezes maiores que o aço provocando fortes tensões no concreto ocasionando a desagregação do cobrimento do concreto, processo conhecido como fenômeno expansivo do interior do concreto [3].

A corrosão também pode ser classificada como um processo de interação destrutiva de um material com o ambiente em que está inserido seja por ações físicas, químicas, eletroquímicas ou a combinação destes. [8] Tratando sobre a corrosão específica do aço é possível determinar dois processos principais sendo eles:

- Corrosão eletroquímica fenômeno que é caracterizado pela formação de pilhas devido a presença de umidade, agua ou uma solução aquosa possível de transporte e que envolva as barras de aço;

- Oxidação direta, onde os átomos do aço reagem diretamente com o oxigênio presente na atmosfera gerando reações químicas que produzem o óxido de ferro. Este processo acentua-se quando a temperatura do ambiente é elevada devido a velocidade de agitação das moléculas [8].

O processo de corrosão ocorre com maior magnitude em obras do setor marítimo, reafirmando que a umidade é um agravante para a corrosão, sendo necessário cuidados com o cobrimento mínimo previsto pela NBR 6118:2003 em estruturas de concreto, assim evitando recuperações futuras [1, 4].

O processo de corrosão pode ser dividido em duas partes sendo a primeira fase caracterizada pela entrada do agente químico até a despassivação da armadura. A segunda fase é marcada pela propagação, onde o processo de corrosão já está em fase muito avançada, transferindo o processo de corrosão para outras partes da armadura [8]. A figura 3 a seguir demonstra a relação entre a vida útil da construção e o grau de corrosão. 


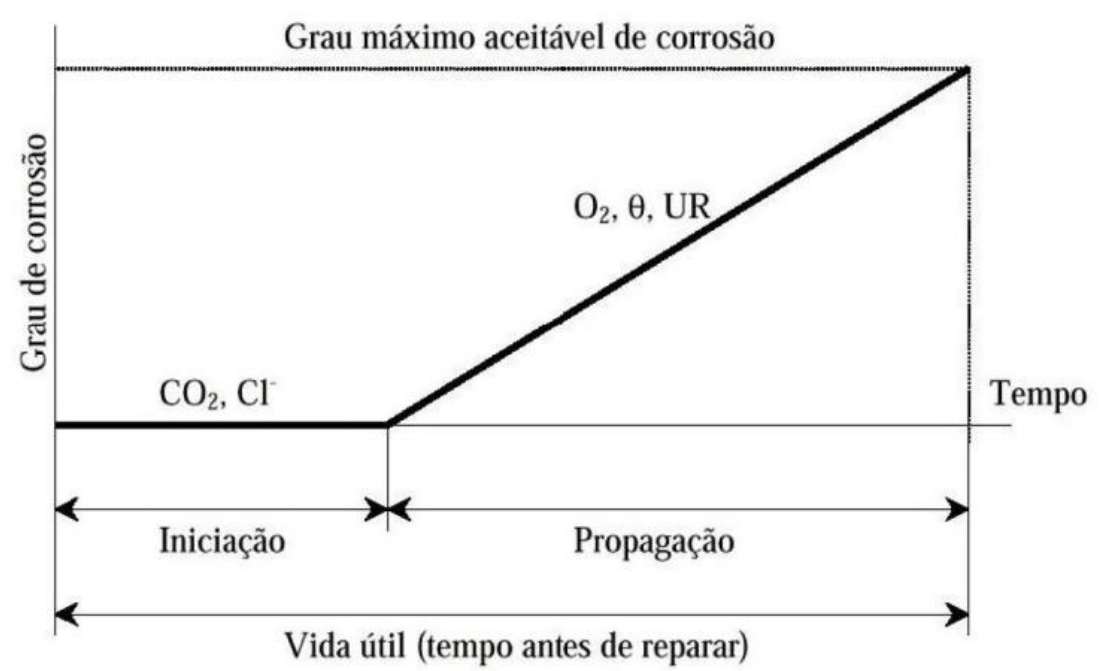

Figura 3 - Relação vida útil $X$ grau de corrosão. Fonte: [8]

Consequente à corrosão das armaduras, o concreto passa a compor 0 processo de corrosão. Os fatores determinantes da corrosão do concreto, sendo eles:

- Fatores mecânicos: relacionados a vibrações mecânicas que possibilitam o contato da armadura com o ambiente externo. A água também apresenta-se como um agente mecânico de degradação, visto que através do movimento e com partículas em suspensão "chocam" com concreto erodindo-o e ocasionando seu desgaste;

- Fatores físicos: caracterizados principalmente pela variação de temperatura, ocasionando dilatações excessivas e consequentemente fissuração do concreto. Choques térmicos também podem ocasionar uma microfissuração na estrutura e comprometer sua qualidade.

- Fatores biológicos: os agentes biológicos, como microrganismos, desenvolvem um ambiente corrosivo para a massa do concreto e para a armadura acelerando o processo de oxidação. Este processo também é realizado pelas bactérias que produzem enxofre e sulfetos.

- Fatores químicos: O contato direto com ambiente externo proporciona a exposição a diversos agentes e texturas, o solo, a água e atmosfera apresentam substâncias químicas capazes de degradar as estruturas de concreto. Dentre eles é possível destacar os ácidos sulfúricos e clorídricos [9]. 


\subsection{CARBONATAÇÃO}

O fenômeno da carbonatação é definido como uma atividade físico-química que limita a vida útil de uma edificação, através da redução da alcalinidade do concreto. A carbonatação afeta diretamente a passividade da armadura favorecendo o processo de corrosão [10].

A partir desta redução são produzidas duas reações entre o dióxido de carbono $\left(\mathrm{CO}_{2}\right)$ presente na atmosfera e o cimento quando há a presença de umidade no ambiente. Como resultado é possível observar uma redução considerável no $\mathrm{pH}$ do concreto que normalmente é encontrado por 12,5 decresce para $8,5[10]$.

Com a figura 4 é possível visualizar como é a atuação do $\mathrm{CO}_{2}$ no concreto, a partir disto é possível verificar a alteração do concreto original que antes era formado por hidróxido de cálcio $\left(\mathrm{Ca}(\mathrm{OH})_{2}\right)$ e passa a compor somente por carbonato de cálcio $\left(\mathrm{CaCO}_{3}\right)$ [10].
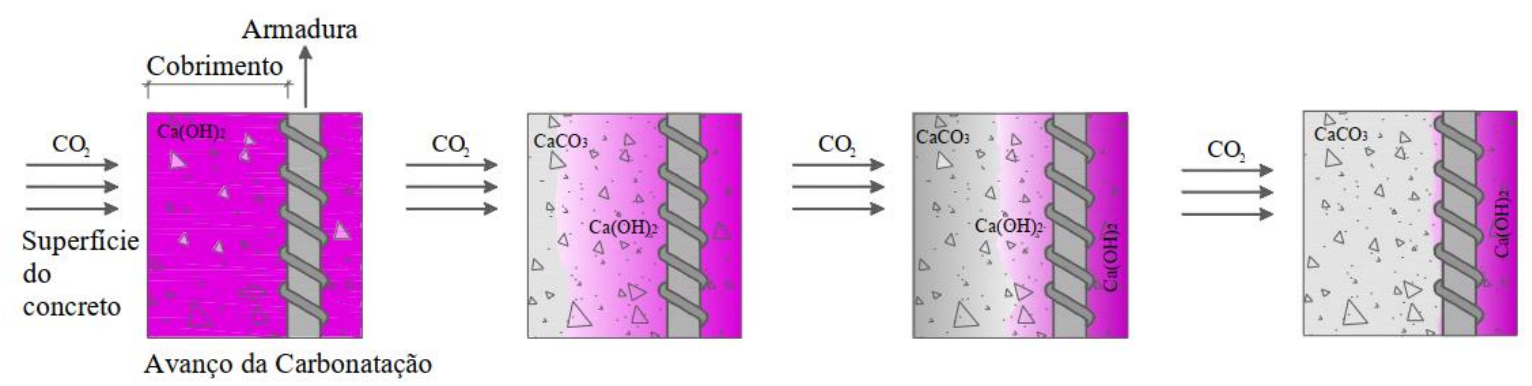

Figura 4 - Processo de carbonatação. Fonte: [9]

De forma geral, é possível descrever o processo de carbonatação a partir da seguinte equação química:

$$
\mathrm{Ca}(\mathrm{OH})_{2}+\mathrm{CO}_{2} \rightarrow \mathrm{CaCO}_{3}+\mathrm{H}_{2} \mathrm{O} \quad \text { Equação } 1
$$

Os principais agentes que intensificam o fenômeno de carbonatação sendo eles principalmente:

- Condições ambientais (através da alta concentração de $\mathrm{CO}_{2}$, temperatura e umidade relativa do ar);

- Condições de exposição;

- Características do concreto; 
- Qualidade da execução;

- Outros fatores como, relação água/cimento, condições de cura, grau de hidratação, presença de fissuras afetam indiretamente no processo de carbonatação [9].

Caso o processo de carbonatação permanecesse somente na camada de cobrimento, este traria benefícios quanto à resistência química e mecânica, porém com os índices de $\mathrm{CO}_{2}$ na atmosfera e a porosidade do concreto este processo alcança a armadura do concreto, corroendo-o [6]. A lei que representa a propagação da carbonatação pode ser descrita a partir da seguinte fórmula:

$-x=k \sqrt[n]{t}$

Equação 2

Onde:

$x$ é a profundidade de penetração da carbonatação;

$k$ constante, em função da porosidade e permeabilidade do concreto;

$n=2$, em ambientes internos $\mathrm{e}<2$ em ambientes externos.

Com base na figura 5 é possível exemplificar as condições ambientais e fatores de agravo:

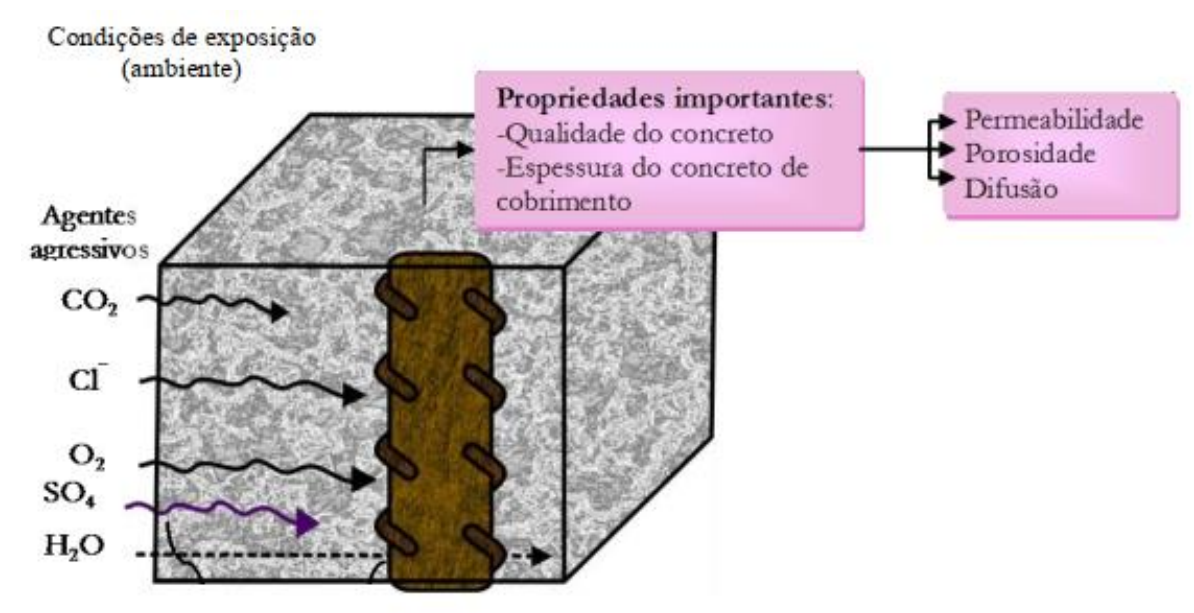

Figura 5 - Processo de carbonatação. Fonte: [9]

Com a ação dos agentes de agressividade o concreto passa se deteriorar e perder qualidade com indícios de fissuração e diminuição da camada de cobrimento do concreto. Devido aos ataques dos sulfatos é possível verificar um processo de lixiviação, biodeterioração e por fim a corrosão do aço e que ocorre após a perca da passividade da armadura [9].

Os ambientes urbanos apresentam elevadas taxas de gases na atmosfera, que se condensam com a água da chuva e precipitam sobre as estruturas de 
concreto, tornando a condição extremamente favorável para o processo de carbonatação. A cidade de São Paulo e outros centros indústrias possuem precipitação com índices de $\mathrm{pH}$ entre 3 e 4 , considerados extremamente agressivos [11].

Os ambientes marinhos também contribuem para 0 processo de carbonatação e corrosão dos materiais, a umidade excessiva e a quantidade de elementos químicos presentes no oceano contribuem diretamente para diminuição da qualidade e da vida útil da estrutura [11].

Atualmente diversos estudos vêm sendo realizados com o objetivo de prevenir ou corrigir o problema da carbonatação no concreto, visto que os índices de emissão de $\mathrm{CO}_{2}$ estão cada vez mais altos e afetam diretamente as estruturas de concreto armado. Uma das metodologias que vêm sendo aplicadas para os concretos carbonatados é a realcalinização eletroquímica (RAE) que basicamente consiste na aplicação de um campo elétrico entre o aço da estrutura à uma solução alcalina com o objetivo de restabelecer esta alcalinidade perdida pelo processo de carbonatação [12].

\subsection{RECALQUES DE FUNDAÇÕES}

O processo de análise de patologias em fundações são consideradas a mais difíceis devido à dificuldade de chegar aos elementos, visto que estão enterrados no solo. As patologias em fundações geralmente são identificadas por rachaduras e fissuras na estrutura e recalques diferenciais na base da construção [13].

O comportamento do solo é o principal agente que deve-se levar em consideração para os estudos de geotecnia. O solo é um sistema complexo que é composto por sólidos, água e vazios de ar, com a evaporação da água o solo pode perder sua estrutura e capacidade carga contribuindo para os rebaixamentos da estrutura [13]. A parcela de solo, agua e ar podem ser exemplifica pela figura 6. 


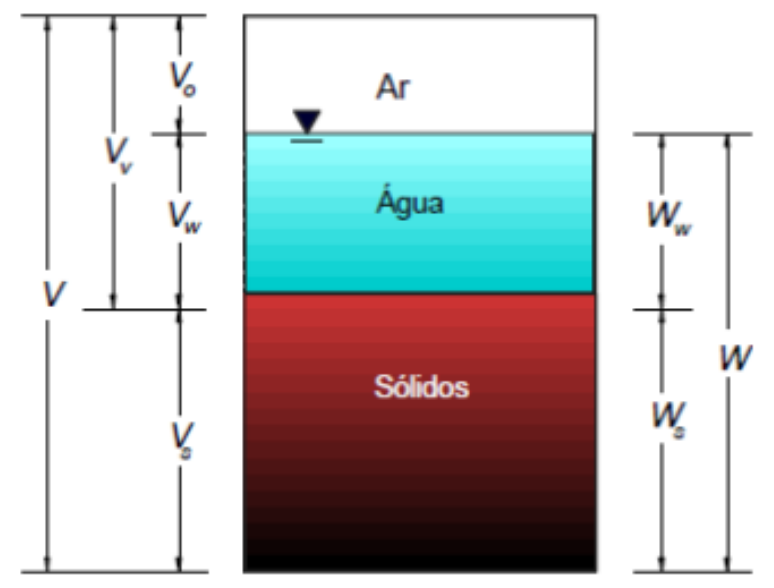

Figura 6 - Componentes e proporção do solo. Fonte: [13]

Outro grande problema encontrado em obras de fundação é o apoio dessas estruturas em solos argilosos, que devido sua complexidade não é possível obter um índice que defina realmente a sua interação solo-estrutura. Geralmente fundações que são apoiadas neste tipo de solo possuem a tendência a rebaixar devido a fácil remoção da água de suas partículas [13].

Diferentemente dos solos argilosos, os solos arenosos possuem uma permeabilidade elevada o que dificulta sua escavação. Este tipo de solo possuem um recalque imediato e para os solos argilosos este processo ocorre progressivamente ao longo do tempo. Para evitar recalque faz-se necessário analisar o grau de compactação do solo, identificando suas características, capacidade de carga e deformações [13].

Para fins de simplificação dos cálculos e pela dificuldade de terminar sua composição por completo, os solos siltosos são classificados entre silto-argiloso ou silto-arenoso, e são levados em consideração como argilas para silto-argilosos e como areia para silto-arenoso [14].

O entendimento e compreensão das camadas e estruturas do solo são indispensáveis para o início de um projeto, as investigações geológicas e geotécnicas devem ser solicitadas de acordo com o tipo de construção ou a critério do engenheiro responsável. Os laudos técnicos do solo servirão como embasamento para possíveis defesas judiciais e principalmente entendimento do funcionamento do solo em caso de surgimento alguma patologia posterior a construção da edificação [14].

O SPT (Standard Penetration Test) consolidou-se como um dos métodos de avaliação mais práticos e acessíveis para sondagem do solo, dentre as informações 


\section{ARTIGO DE REVISÃO I review article}

retirada deste teste está a resistência a penetração, o nível do lençol freático e também uma amostra de solo a cada metro perfurado. A ABNT NBR 8036:1983, determina a quantidade furos que deverão ser aplicados no terreno a ser construído de acordo com metragem quadrada da edificação [15], conforme a tabela 4.

Tabela 4 - Números de furos para sondagem SPT

\begin{tabular}{|c|c|}
\hline Área de projeção em planta & Quantidade de sondagens \\
\hline \multirow[t]{2}{*}{ Até $1200 \mathrm{~m}^{2}$} & 1 para cada $200 \mathrm{~m}^{2}$ \\
\hline & 1 a mais para cada $400 \mathrm{~m}^{2}$ que \\
\hline \multirow[t]{2}{*}{ De $1200 \mathrm{~m}^{2}$ a $2400 \mathrm{~m}^{2}$} & excede $1200 \mathrm{~m}^{2}$ \\
\hline & Necessária avaliação específica por \\
\hline Acima de $2400 \mathrm{~m}^{2}$ & projeto \\
\hline
\end{tabular}

Fonte: [15]

De acordo com a tabela 4 acima, a NBR prevê algumas exceções sendo elas:

- Duas sondagens para área de projeção em planta de até $200 \mathrm{~m}^{2}$;

- Três sondagens para área de projeção em planta entre $200 \mathrm{~m}^{2}$ e $400 \mathrm{~m}^{2}$ [15].

Existem diversas causas que o recalque em fundações pode derivar sendo os principais: superposição de pressões, deficiência nas investigações geológicas e geotécnicas, fundações sobre aterro, atrito negativo, alteração da função da estrutura para o qual foi dimensionado, rebaixamento do lençol freático, infiltrações ou erosões, escavações próximas entre outros diversos motivos que propiciam o recalque [16].

Os recalques diferenciais são na maioria das vezes visíveis a olho nu e suas consequências são desastrosas na estrutura do edifício podemos observar na figura 7 um modelo com os recalques realçados um e um exemplo real de obra.
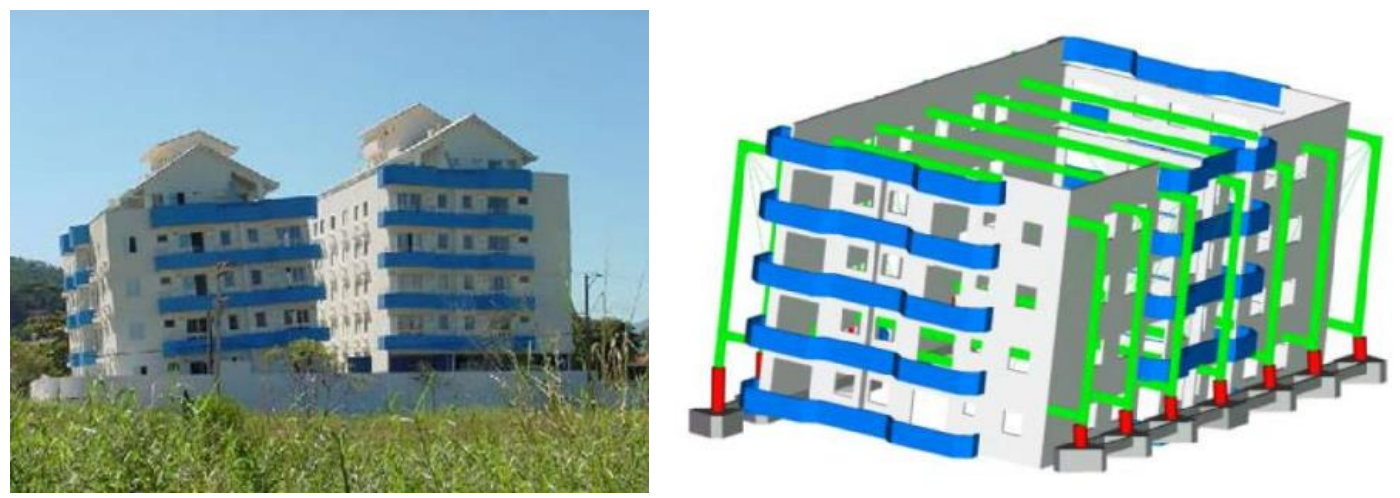

Figura 7 - Recalque diferencial em edificação de 4 pavimentos. Fonte: [16] 
No caso da figura acima o autor esclareceu que os a presença de solos compressíveis e com pouca capacidade de carga ocasionou o deslocamento de aproximadamente $30 \mathrm{~cm}$ no piso e consequentemente a diferenciação do alinhamento com o outro prédio. Como alternativas para solução dos problemas de recalques foram elaborados projetos de recuperação com objetivo de elevar o edifício por macacos hidráulicos com apoio de fundações provisórias e estruturas metálicas. Após a suspensão do edifício e o posicionamento na cota inicial (figura 8) foram refeitas as fundações permanentes, bem como os reforços da vigas e pilares do edifício [16].

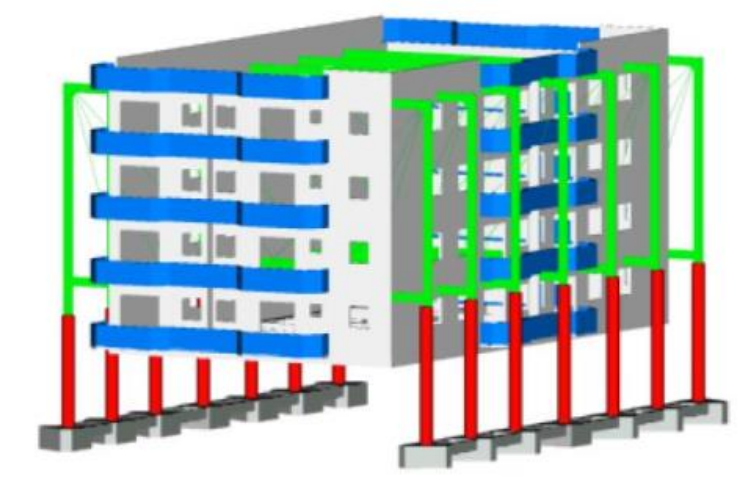

Figura 8 - Projeto de reabilitação de fundações Fonte: [16]

Para reabilitação de um edifício acometido por patologias, os laudos estruturais são indispensáveis, através destes é possível determinar a relação de custo benefício entre a restruturação do edifício ou a sua demolição.

\section{CONSIDERAÇÕES FINAIS}

Os estudos dos processos patológicos demonstram relativa importância tanto quando o projeto e execução das construções, as análises das patologias e da sintomatologia apresentada devem ser realizadas com bastante cautela, visto que traz grande economicidade e segurança para os usuários das edificações. 0 estudos relativos as patologias agregam valor ao imóvel servindo como base para formulação de laudos técnicos e manuais de utilização da construção.

As diversas patologias que acometem uma estrutura, todas influem diretamente na qualidade de vida usuário seja do ponto de vista estético ou da 


\section{ARTIGO DE REVISĀO I review article}

segurança estrutural. Cada vez mais são aplicados estudos com o objetivo de prevenir e reabilitar as construções sem que seja necessária a demolição do edifício. Atualmente o ramo da engenharia diagnostica busca a preservação dos registros históricos em construção através dos controles de patologias, diversos autores desenvolvem equipamentos e metodologias para recuperação por completo da estrutura.

\section{REFERÊNCIAS}

[1] OLIVARI, G. Patologias em edificações. (Monografia). Graduação em Engenharia Civil - Universidade Anhembi Morumbi. São Paulo. 2013.

[2] OLIVEIRA, D. F. Levantamento de causas de patologias na construção civil. (Monografia) UNIVERSIDADE FEDERAL DO RIO DE JANEIRO. Rio de Janeiro. 2013.

[3] LOTTERMANN, A. F. Patologias em estruturas de concreto. (Dissertação) UNIVERSIDADE REGIONAL DO NOROESTE DO ESTADO DO RIO GRANDE DO SUL. ljuí .2013.

[4] ABNT - ASSICIAÇÃO BRASILEIRA DE NORMAS TÉCNICAS. NBR 6118. Projeto de estruturas de concreto - Procedimento. Rio de Janeiro: ABNT. 2007.

[5] ABNT - ASSOCIAÇÃO BRASILEIRA DE NORMAS TÉCNICAS. NBR 15575. Desempenho de edificações habitacionais. Rio de Janeiro: ABNT. 2013.

[6] SOUZA, V. C.; RIPPER, T. Patologia, recuperação e reforço de estruturas de concreto. São Paulo: Editora PINI. 1998.

[7] THOMAZ, E. Trincas em edifícios: causas, prevenção e recuperação. São Paulo: Editora PINI: IPT: EPUSP, 1989.

[8] HELENE, P. R. L. Contribuição ao estudo da corrosão em armaduras de concreto armado. (Dissertação) UNIVERSIDADE DE SAO PAULO ESCOLA POLITECNICA. São Paulo. 1993.

[9] GENTIL, V. Corrosão. 4ํe ed. Editora LTC. Rio de janeiro, 2003.

[10] POSSAN, E. Modelagem da carbonatação e previsão de vida útil em estruturas de concreto em ambiente urbano. (Tese) Universidade Federal do Rio Grande do Sul. Porto Alegre. 2010.

[11] HELENE, P. R. L. Manual para Reparo, reforço e Proteção de Estruturas de Concreto. $2^{\text {a }}$ ed. São Paulo: Pini, 1992. 
[12] RIBEIRO, P. H. L. C. MEIRA, G. R. FERREIRA P. R. Realcalinização de concretos carbonatados - influência de características do material. VI Congresso Internacional sobre Patología y Recuperación de Estructuras. Argentina. 2010.

[13] ORTIGÃO, J. A. R. Mecânica dos Solos dos Estados Críticos. 3. ed. Rio de Janeiro. 2007.

[14] BOTELHO, M. H. C.; CARVALHO, L. F. M. Quatro edifícios, cinco locais de implantação, vinte soluções de fundações. 1. ed. São Paulo: Edgard Blucher, 2007.

[15] ABNT - ASSOCIAÇÃO BRASILEIRA DE NORMAS TÉCNICAS. NBR 8036.

Programação de sondagens de simples reconhecimento dos solos para fundações de edifícios. Rio de Janeiro: ABNT. 1983.

[16] SANTOS, G. V. Patologias devido ao recalque diferencial em fundações. (Dissertação) UNIVERSIDADE Brasília. 2014. 